IZA DP No. 1369

Shifting Perspectives in Pensions

Marek Góra

Edward Palmer

October 2004 


\title{
Shifting Perspectives in Pensions
}

\author{
Marek Góra \\ Warsaw School of Economics \\ and IZA Bonn \\ Edward Palmer \\ Uppsala University
}
Discussion Paper No. 1369
October 2004

\author{
IZA \\ P.O. Box 7240 \\ 53072 Bonn \\ Germany \\ Phone: +49-228-3894-0 \\ Fax: +49-228-3894-180 \\ Email: iza@iza.org
}

\begin{abstract}
Any opinions expressed here are those of the author(s) and not those of the institute. Research disseminated by IZA may include views on policy, but the institute itself takes no institutional policy positions.

The Institute for the Study of Labor (IZA) in Bonn is a local and virtual international research center and a place of communication between science, politics and business. IZA is an independent nonprofit company supported by Deutsche Post World Net. The center is associated with the University of Bonn and offers a stimulating research environment through its research networks, research support, and visitors and doctoral programs. IZA engages in (i) original and internationally competitive research in all fields of labor economics, (ii) development of policy concepts, and (iii) dissemination of research results and concepts to the interested public.
\end{abstract}

IZA Discussion Papers often represent preliminary work and are circulated to encourage discussion. Citation of such a paper should account for its provisional character. A revised version may be available directly from the author. 
IZA Discussion Paper No. 1369

October 2004

\section{ABSTRACT}

\section{Shifting Perspectives in Pensions*}

This paper addresses the questions of what is an economically efficient pension system, what are the externalities and what are the risks of the four alternative pension systems: financial defined contribution (FDC), notional or non-financial defined contribution (NDC), financial defined benefit (FDB) and non-financial defined benefit (NDB). A main contribution of the paper is the development of the concept of NDC, itself a new construction in pension economics. An important conclusion is that NDC is neutral in terms of externalities. It manages the risks and eliminates the negative externalities associated with traditional public NDB schemes, and in a manner similar to FDC schemes.

JEL Classification: D6, D8, D91, G23, H23, H55, J26

Keywords: pensions, NDC, FDC, notional account systems, financial account systems, funding, externalities, risks, defined contribution, government debt

Corresponding author:

Marek Góra

Warsaw School of Economics

Aleja Niepodleglosci 162

02554 Warszawa

Poland

Email: Marek.Gora@sgh.waw.pl

\footnotetext{
* The authors would like to express their appreciation for valuable comments received on an early draft of this paper provided by Agnieszka Chlon, Christopher Daykin, Agneta Kruse, Heikki Oksanen, Michal Rutkowski, Anna Ruzik and Gert Wagner. The usual disclaimer holds. The authors express their gratitude to The Center for Economic and Social Research (CASE) in Warsaw for financial support for this project.
} 


\section{INTRODUCTION}

Pensions are nowadays a part of mainstream economics, but at the same time the concepts are inherited from a framework developed quite a long time ago, when pensions were an important topic mainly in the insurance and social policy literature. Our focus in this paper is on universal pension schemes, schemes that are mandatory and apply to everyone in a country. The emergence of NDC has added a new pension model. The entrance of NDC into the choice arena brings with it a need for greater precision in the use of terminology in order to create a clearer picture of the differences and similarities of options for public pension policy. This paper creates a systematic conceptual framework that can be applied to evaluation of the relative merits of pension schemes, and then does this.

Our point of departure in this paper is four possible pension regimes, identified using two dichotomies - defined contribution versus defined benefit and financial versus nonfinancial. This gives us the terms financial defined contribution (FDC), financial defined benefit (FDB), non-financial defined benefit (NDB) and non-financial, or notional defined contribution (NDC). ${ }^{1}$ Instead, with the exception of possible demographic funding, their assets are claims on future contributions.

We use the term externality in this paper to describe the effect of a pension scheme on the supply of labour and saving. We realize that this is a new and perhaps controversial use of the term externality, which is usually thought of as being the result of interdependence among agents - consumers or producers. However, the word externality is particularly suited to our discussion. A pension scheme produces an insurance service, whose produce is the utility derived from the service by participants in the scheme. In this sense, if the scheme distorts the supply of labour, for example by creating a tax wedge, this can be viewed as a negative externality. If the scheme affects saving negatively, as a pay-as-you-go scheme may do if it substitutes for private saving, we call this a negative externality. If it creates saving we call this a positive externality. In this case the pension scheme creates a flow of money into the financial sector.

The financial instruments held in the financial scheme determine, however, whether a scheme can contribute to national saving and growth, which is what we label a positive externality. DC schemes are efficient, and have no negative externalities, whereas DB

\footnotetext{
${ }^{1}$ Before Sweden legislated NDC in 1994, it was generally thought that NDC was an impossible construction. NDC as it has emerged in practice is described and discussed in Palmer (1999, 2000 and 2002) and Settergren (2001) for Sweden; Chlon, Góra and Rutkowski (1999) and Góra (2001a) for Poland; Fox and Palmer (1999) for Latvia and Franco (2002) for Italy.
} 
schemes are not efficient, and do create negative externalities. The development of these ideas - which we refer to as the economic content of universal pension schemes - is a major focus of this paper.

We begin by considering the economic meaning of defined contribution and defined benefit. Well into the 1990s many experts maintained that the choice for public pension schemes is limited to two general models: Either funded or unfunded (pay-as-you-go). Many associate funded with private management and defined contribution (DC), and unfunded with public management and defined benefit (DB). This imprecision has led to an imprecise discussion of the important issues in pension economics.

The literature comparing systems is often confused or unclear because the terminology as it is usually used avoids some of the key issues. A number of questions need to be asked, but frequently are not: Is a scheme more or less efficient? Which schemes minimise negative externalities, which embody positive externalities? Which design better manages different risks? What is the meaning of funding? How do different designs of systems deal with social goals? What is the meaning of private and public? We analyze the four competing schemes FDC, FDB, NDB and NDC - in the context of these questions.

In Section 2 we begin by defining DC and DB in terms of efficiency. In Section 3 we define NDC as it has taken form during the 1990s and compare it with FDC. Section 4 discusses NDC bonds and the rate of return. In Section 5 we discuss the meaning of funded and unfunded in the context developed in this paper. Section 6 applies the nomenclature developed to discuss pension systems in terms of externalities. Section 7 analyzes how the four types of systems deal with risk. Section 8 brings social goals into the discussion. Section 9 addresses directly the confusion about what's "private" and what's "public". In the last section we draw conclusions.

\section{ECONOMIC EFFICIENCY AND PENSION SCHEMES}

Using the dichotomies defined contribution versus defined benefit and financial versus nonfinancial, the four possible pension schemes are:

\begin{tabular}{|l|c|c|}
\hline & Financial & Non-financial \\
\hline Defined Benefit & FDB & NDB \\
\hline Defined Contribution & FDC & NDC \\
\hline
\end{tabular}


A definition of an economically efficient pension scheme is a scheme that does not influence individual work-leisure and consumption-saving decisions. To begin with, in terms of individual decisions an economically efficient pension scheme is one where the present value $(\mathrm{PV})$ of accumulated individual contributions in any period $(\mathrm{t})$, valued at the internal rate of return is exactly the value of the individual's claim on assets in the scheme, and is exactly the value of the benefit that could be obtained by liquidating individual account holder i's account at the end of the period, $t$.

$$
\mathrm{PV}_{\text {it }} \text { (assets) }=\mathrm{PV}_{\text {it }}(\text { benefit })
$$

In a life-cycle perspective, the individual pays contributions to a scheme that entitles him to an equivalent stream of consumption in the future. The only possible distortion of a mandatory scheme is through its effect on liquidity when young, since usually one cannot borrow using pension account assets as collateral. A voluntary contractual scheme is also illiquid, but freely chosen illiquidity.

Aggregate assets and liabilities are the sum of their individual counterparts:

$$
\mathrm{PV}_{\mathrm{t}} \text { (aggregate assets) }=\mathrm{PV}_{\mathrm{t}} \text { (aggregate liabilities) }
$$

Both FDC and NDC schemes fulfil these conditions (1) and (2). DB schemes fulfil condition (2) but not condition (1). In the aggregate a scheme is always financed, although how financial balance arises is by definition a design feature that distinguishes DC and DB schemes. By definition the benefit entitlement in DB is defined according to a rule and the contribution rate adjusts - i.e. a tax is levied - to create financial balance according to (2). DB schemes entail taxes on some to provide transfers to others, whereas, in principle, DC schemes involve only reallocation of an individual's consumption over the lifetime. In DB, the outcome for specific individuals of the process leading to the fulfilment of condition (2) can only be known ex post. In DC it is known in the current accounting period t.

By definition, DB schemes have some form of redistribution, of which there are endless possibilities. In principle, DC schemes do not, although the convention applied in practice of computing annuities with unisex life expectancy in public schemes breaks with this principle. We address the important issue of guarantees for the poor and, more generally, redistributional pension policy in a separate section below. Since NDC is still a relatively new concept in the literature, we begin by describing NDC in detail, comparing it with FDC. 
The DC accumulation period. In both FDC and NDC accounts are created by applying a given contribution rate to earnings, which yields the defined contribution. It is easiest to view the contribution rate as fixed - with the same rate for all individuals and all generations. In FDC it can be decreased without creating a tax. In NDC a decrease in the contribution yields unfunded liabilities to participants, which have an exact value according to equation (1). If these are not recognized, this is equivalent to levying a tax on participants, which is tantamount to taxing the funds in an FDC scheme. If the liabilities are recognized and honoured, then this will be at the expense of future taxpayers. ${ }^{2}$ An increase in the contribution rate leading to higher contributions gives a commensurately larger present value for individual account values and benefits in both NDC and FDC schemes. The contribution of NDC is the enablement of the exact calculation of the system's debt to all individuals at any time $t$, according to equation (1), which gives the property of transparency. (DB schemes are not transparent in this respect.) With traditional public NDB schemes this is generally not possible since one usually does not know whether an individual has fulfilled the DB conditions until the very time of retirement.

The rate of return on accounts. The rate of return in the NDC scheme is the rate that guarantees that individuals over all generations will not have to pay contributions that do not yield a benefit in accordance with equation (1). In terms of condition (2), it is the internal rate of return, the rate that equates assets and liabilities. In a state with a fixed workforce-agedistribution and fixed demographic benefit payment profile, this is satisfied with an NDC rate of return based on the (instantaneous) rate of growth of the contribution base, which is determined by the rate of growth of productivity, $g$, and the labour force, $\lambda$ (Palmer 1999, Valdes-Prieto 2000), i.e. the Samuelson (1958) condition. Their analysis suggests, however, that under some circumstances, the Samuelson rate of return of $\lambda+\mathrm{g}$ would not be sufficient to maintain financial equilibrium. Namely, when workforce and retirement profiles change over time, the balance between assets and liabilities can be affected. ${ }^{3}$

In (N)DC and (F)DC, if for whatever reason the present value of aggregate assets (A) < aggregate liabilities (L), account values and annuities must be accredited with a lower rate of return than $\mathrm{g}+\lambda$ in NDC and $\mathrm{r}$, the financial market rate of return, in FDC. This defines a

\footnotetext{
${ }^{2}$ Countries may nevertheless choose to do this, for example, in order to gradually convert to an FDC scheme, which in a three generational perspective could increase total welfare. Lindbeck and Persson (2002) discuss the issue of welfare gains from conversion from non-financial to financial DC schemes.

${ }^{3}$ Exactly how this occurs is shown in extensive work performed in conjunction with the Swedish pension reform. The problem is discussed in Settergren (2001), with references to Swedish language publications.
} 
factor $\varphi_{t}=1-\mathrm{PV}(\mathrm{A})_{t} / \mathrm{PV}\left(\mathrm{L}_{\mathrm{t}}\right)$, itself a function of variables that are well-defined and are discussed below. ${ }^{4}$ This gives the internal rate of return $\mathrm{g}+\lambda+\varphi$ in NDC and $\mathrm{r}+\varphi$ in FDC.

The rates of return in NDC and FDC as just defined can vary between individuals in the same birth cohort, depending on when they enter and leave the scheme, as well as between birth cohorts, for the same reason. In NDC, changes in productivity, labour force growth and $\varphi_{\mathrm{t}}$ determine the real rate of return for individuals. In FDC, market fluctuations, individual portfolio choice and $\varphi_{\mathrm{t}}$ determine the real rate of return.

As regards NDC, it can be argued that for reasons of equity, ${ }^{5}$ the rate of growth of contributions per contributor, i.e. long-run productivity growth, $\mathrm{g}$, is a preferable rate of return to accredit accounts with, instead of $g+\lambda$. Those who argue in favour of this rate refer to the fact that if account values grow at the rate $g$, ceteris paribus, pension commitments and eventually newly converted pensions will grow at the same rate as the per capita wage, which means the ratio of an average newly granted benefit to an average wage is constant over time - and generations. ${ }^{6}$ Ceteris paribus, if $g$ is the chosen rate of return and if $\operatorname{PV}\left(A_{t-1}\right)=P V\left(L_{t-1}\right)$ and $\lambda_{t}<0$, then by definition $\varphi_{t}$ captures the effect of this negative growth in contributors. ${ }^{7}$ If the system bases the rate of return on $g$ alone, then $\lambda>0$ can lead to an uncommitted increase in the system's reserves, and requires an additional legislative rule to determine the distribution of a surplus. In sum, an NDC scheme is a closed scheme in aggregate financial balance. In this sense, it is one step removed from arbitrary political decisions, just as FDC, albeit politicians can always tax the accounts in both NDC and FDC schemes.

The calculation of an NDC annuity. Since NDC is non-financial, the cash value of the present value of assets at retirement must be paid out as a life annuity. An NDC annuity is calculated by dividing the individual's capital balance for a chosen age of retirement by years of life expectancy at this age for the individual's birth cohort. ${ }^{8}$ Ceteris paribus, an NDC scheme can afford to give individual annuities a rate of return equivalent to the real growth of

\footnotetext{
${ }^{4}$ In the Swedish NDC scheme this mechanism is central to what is called automatic balancing, described in Settergren (2001). See also the quantitative results reported in the Annual Report of the Swedish Pension System published by the Swedish National Social Insurance Board (RFV).

${ }^{5}$ Sweden has formulated its system based on this argument. See Palmer (1999) and Settergren (2001).

${ }^{6}$ One might argue that the least volatile of these two alternatives would be the best. Whether either $g$ alone or $g$

$+\lambda$ is the most volatile is an empirical issue, the answer to which depends on the period and country.

${ }^{7}$ As the system is constructed in Sweden, if $\mathrm{PV}\left(\mathrm{A}_{\mathrm{t}-1}\right)>\mathrm{PV}\left(\mathrm{L}_{\mathrm{t}-1}\right)$ and individual account values have previously been deflated because the balancing mechanism has been triggered, then additional indexation occurs until the "index without balancing (determined by the growth rate $\mathrm{g}$ ) is once again achieved.

${ }^{8} \mathrm{~A}$ minimum retirement age is needed to specify when a benefit can first be claimed, but there is no upper limit to when a benefit must be claimed, and benefits can be claimed in part or in whole and in principle are taxed with the same rate as earned income, in order to avoid introducing other possible distortions.
} 
the nominal contribution base, i.e. $\mathrm{g}+\lambda$ plus the rate of inflation (Palmer 1999). ${ }^{9,} 10$ In FDC schemes it is possible to provide the option of a lump-sum cash payment at retirement. This, however, fits poorly with the philosophy of a universal scheme, the purpose of which is to prevent poverty in old age.

A system that bases the rate of return on growth of the contribution base, $g+\lambda$, estimates of life expectancy using cohort projections (as opposed to using cross-section life expectancy at the time of calculation) that only give rise to random differences between the ex post value of deviations from ex ante with expected value of zero, and that earns a rate of return on its technical fund of at least $g+\lambda$ will be in or close to balance, i.e. the ratio of assets to liabilities will be close to unity. The remaining risk for long-term negative balance arises due to two factors. The first is that money has to be paid out sooner in year $\mathrm{t}+1$ compared to year $\mathrm{t}$, i.e. the turnover time for money in the system has decreased or increased (see Settergren 2001 for a discussion), and second, because in practice calculated rates of return have to be based on lagged data, and in a perpetual downturn adjustment is always a little behind what is needed to maintain balance. ${ }^{11}$ Regardless of their source, deviations from the "perfect world" will be captured by $\varphi_{t}$. Finally, note that NDC and FDC schemes react to changes in the demography in a similar manner through the effects on their internal rates of return.

Technical (demographic) reserves. Large birth cohorts create reserves that will be needed to help pay their pensions when they retire. These reserves need to earn at least the same rate of return accredited accounts of workers. A greater return creates uncommitted reserves, and a smaller return creates a financial deficit, ceteris paribus, and both these situations affect the value of $\varphi_{\mathrm{t}}$. The technical reserves in the NDC scheme are tantamount to the reserves in an FDC scheme.

In sum, in terms of efficiency, NDC matches FDC in not creating distortions that affect individual work-leisure decisions given that both are mandated. Whereas public NDB schemes contain built-in tax-transfer redistribution, they are not efficient in the sense of equating the present value of individual assets and benefits. Whether the inefficiency in DB inherent schemes distorts individual behaviour is on the other hand an empirical question that

\footnotetext{
${ }^{9}$ Note that although we are only interested in real values in this paper, all the results hold in nominal terms, that is, benefits are also price indexed.

${ }^{10}$ The Swedish and Italian NDC annuities are computed at the outset assuming a rate of economic growth of 1.6 $\%$ in Sweden and $1.5 \%$ in Italy. The Swedish annuity is adjusted for the difference between the actual annual outcome and this "norm".

${ }^{11}$ This was illustrated in Palmer (1999).
} 
would have to be examined from situation to situation. So the conclusion is that FDC and NDC schemes are neutral by definition, whereas DB schemes may not be. We discuss the issue of consumption and saving in the following section.

Finally, note that it is possible to have a financial defined benefit (FDB) scheme that in principle is constructed along the lines of DC. This implies, however, that the right contribution rate needed to finance the scheme is established from the beginning - implicitly with notice given to participants that a fixed pension age with decreasing mortality implies cohort differentiation of contribution rates so as to create intergenerational financial balance.

If an FDB scheme requires a non-cohort specific increase in the contribution rate to meet defined benefit commitments, then we are back to the issue of adjustment through a tax rather than through the internal rate of return. If the employer pays the bill at the expense of profits, instead of earnings, then meeting commitments entails levying a "tax" on shareholders. The question is, however, to what extent the increased labour costs are really borne by profits and shareholders in the long run. There is empirical evidence, e.g. Palmer and Palme (1988) that with time increases in labour costs above those justified by increases in productivity are passed over to wage earners. ${ }^{12}$

As a final observation, we note that NDC also helps establish a new idea in public finance. Since the institutionalisation of Keynesian economics some economists have argued that there is no real distinction to be made between tax sources, all taxes are perceived by individuals as being the same, in spite of their uses. Those who adhere to this view mean there is no particular reason to prefer contributions on earnings to the value added tax as a source of finance for pensions. The NDC concept breaks with this idea. In principle, a contribution to an NDC scheme should be treated as a premium payment. Although by definition there will always be an implicit tax compared to the financial market rate, if the latter is greater in either NDC or FDC, ${ }^{13}$ there is no tax wedge in the sense of an imperfect link between contributions and benefits.

\footnotetext{
${ }^{12}$ This evidence is based on econometric evaluation the evolution of prices, profits and real wages before and after substantial adjustments in employer contribution rates in Sweden in the mid-1970s.

${ }^{13}$ As we discuss in the following, an FDC scheme that holds government bonds that finance public consumption entails a tax, and creates no saving.
} 


\section{NDC BONDS}

In the Golden Rule steady state, the possible rate of return in the NDC scheme is the rate of growth of the contribution base, $g+\lambda$, which is also the rate of growth of national income. ${ }^{14}$ Granted, not all taxes are based on this base, but, generally speaking, we can view both consumption and wage taxes as growing at this rate. In principle, the commitment of the NDC scheme can be seen as being backed by an NDC bond which offers the rate of return $\mathrm{g}+\lambda$. This bond could be created and shares based on the public liability could be issued to participants, although this just adds transaction costs in practice. Seen in this perspective NDC is a way to roll public debt forward in time, which is exactly what happens when financial account schemes buy government bonds issued on the financial market. This way of thinking is tantamount to how we usually view a government bond that is traded on the financial market. ${ }^{15}$ In principle, NDB can be viewed in the same way, although by definition, it is not possible to distribute the shares to individual working participants, since individual shares are usually unknown until retirement.

The important difference between FDC and NDC schemes is that the NDC scheme has only one available asset, a government bond, whereas financial account schemes can also invest in non-government financial instruments. If we accept the idea that NDC is an implicit government bond fund, holding a perpetual NDC bond, then if there's to be a real difference between FDC and NDC schemes, the financial account system must invest in non-government financial instruments. In this sense, a financial scheme that only purchases government bonds can be viewed as an NDC scheme, but with additional costs due to the cost of issuance, marketing and transactions of government debt instruments. In this case $r=g+\lambda+\tau$, where $\tau$ is the tax rate on wages needed to finance the difference between the NDC bond and the marketed government financial instruments.

\section{FUNDING}

The concept of "funding" must be discussed in terms of whether we focus on the assets behind the scheme or whether we focus on the question of saving. This gives two concepts. First, if being backed by financial assets, is the criterion for funding, which is the usual view,

\footnotetext{
${ }^{14}$ The rate of return in the NDC scheme is by nature a diversification of the "portfolio" of all economic activity, not just assets traded in the more sophisticated financial markets. In fact, a major difference between the assets underlying the returns of typical FDC as opposed to NDC schemes is that in reflecting the growth of the economy, NDC also reflects the performance of a large number of less productive investments, not usually financed and traded through the equity markets.

${ }^{15}$ Note that this idea can be compared to Wicksell's quantity theory of money.
} 
an FDC scheme is fully funded by definition. An NDC scheme is also fully funded, however, in the sense that it is backed by a ("Buchanan") bond of the type described above. NDB and FDB are also funded in the sense that they fulfil criterion (2), but individual shares are unidentifiable. What separates DC from DB is whether the assets are traded in the financial market.

In the second concept of funding FDC and FDB premium payments can create saving, if debt instruments purchased are not used to finance current (public) consumption, i.e. as long as financial assets cover deferred consumption. ${ }^{16}$ This saving yields investments that can yield higher per capita income in the future. NDC, nor for that matter NDB, are funded in this sense, however, since the underlying assets are not traded but represent debt rolled over into the future. In other words, savings in private instruments constitute a claim on future production revenues (or profits), government bonds entail a claim on future tax revenues of the government.

Finally, the issue of funding can also be discussed in another sense. In FDC and FDB schemes saving occurs only as long as the increase in the fund exceeds the payments made, otherwise there is dissaving. With a steady state population this means that in maturity the fully funded scheme corresponds to a demographic reserve fund in a non-financial scheme, i.e. an NDC scheme. In this sense an FDC scheme is only "partially" funded, as changes in the mature fund in steady state are equivalent to the demographically driven changes in an NDC scheme. Both have the same effect on national saving, given that the FDC scheme has reached maturity. This leads us to conclude that there is no such thing as an "unfunded" scheme in economic terms. Instead, what matters for pension systems are the externalities associated with their design, discussed in the next section.

\section{EXTERNALITIES}

Externalities arise due to effects on work-leisure and consumption-saving decisions. We begin with the negative externalities. First, for work-leisure decisions, as we have already argued DC fulfils the criterion for efficiency. DC schemes are generally superior to DB schemes in this sense, and in practice are at least as good as DB schemes depending on the construction of the latter and individual behavioural responses.

\footnotetext{
${ }^{16}$ We note that the government can borrow for both consumption and investment. This raises the question of whether the government should borrow to change the time profile of consumption, for example, through investment projects.
} 
Second, because of the direct link between contributions and benefits, the incentive to evade payment in a universal public system is minimised with DC. In other words, future taxes arising due to free-riding and myopia are minimized, although not necessarily eliminated. This does not mean that well-motivated redistribution to poor pensioners is eliminated. Instead this is covered by a separate, explicit DB mechanism at the foundation of the system, such as a guarantee, discussed in a separate section below. Whether the direct link between contributions and benefits in FDC and NDC encourages participation is an empirical question. ${ }^{17}$

Thirdly, NDC and FDC schemes are neutral with regard to the individual retirement decisions. In calculating the loss in lifetime resources (tax on continuing to work) from not leaving the labour force, people will retire early if this is in their interests, ${ }^{18}$ but this is not consistent with the interests of society at large. This externality is the mirror image of the risk of moral hazard.

Fourth, NDC and FDC can prevent opening the arena for groups of people who will argue that they should have special treatment in the system. Special DB rights, ${ }^{19}$ perhaps justifiable when granted, can easily become unjustifiable as the economic environment or other circumstances change. ${ }^{20}$ Politicians can trade grants of special rights for political support, while those who have to pay are usually not consulted, and usually do not know that they will have to pay until it's too late to bring the politicians who legislated the rules to account. In the FDC and NDC framework money must be transferred into the insurance schemes to pay for special rights, which puts a price tag on these decisions.

Fifth, FDC and NDC schemes automatically control the size of the pension system, whereas by definition, DB gives rise to an increasing future tax wedge increasing the risk that the pension system will put a damper on growth.

Finally, both NDC and FDC are neutral vis á vis their effect on labour mobility, whereas some DB schemes can impede labour mobility due to the conditions specified in the DB contract to qualify for a "full" benefit.

\footnotetext{
${ }^{17}$ This depends on, among other things, the overall economic, legal and administrative environment.

${ }^{18}$ This is the message of the 12 country examples published in the Gruber and Wise (1999) cross-country study of incentives and retirement.

${ }^{19}$ In Eastern and Western Europe, but in Latin America as well, there is a legacy of granting privileges to many special groups. One of the difficult issues in reforms in transition countries in the 1990s has been the need to phase out special privileges granted under previous regimes (cf. Fox and Palmer 2001a).

${ }^{20}$ For example, in the old Soviet regime, poor working conditions were subsidized by granting early pension rights.
} 
Summing up, FDC and NDC do not create negative externalities, whereas DB schemes can. The next question is whether positive externalities can be created by either of these systems. The answer is implicit in the commonly held view of why FDC dominates NDC. NDC can only roll a debt forward in time albeit at no cost, while FDC can create real saving. To the extent that the financial account system does not replace or crowd out private initiatives that would have evolved instead, mandated FDC schemes can force a country to save more. In a dynamic, efficient setting where mandatory saving does not replace similar private saving, FDC non-government-bond saving will also contribute to economic growth through financing real investment.

FDB can contribute to saving, although there is a question of how contemporary workers respond if the contribution rate is increased to transfer money to other participants. If the individual budget restriction is iso-elastic, then a net tax represents a parallel downward shift in available resources for both consumption when young and when old. At the same time, the consumption of net recipients of transfers increases, but saving may fall for this group. The risk that this process could create less saving over time would make FDC at least as good or better than FDB on terms of efficiency.

Finally, there is second positive externality of FDC compared with NDC. If mandated financial schemes invest savings in non-government financial market assets then this promotes financial market development even more strongly. There is some evidence of this, for example, for emerging financial markets. ${ }^{21}$

\section{MANAGING RISKS}

The literature generally recognises five risks. ${ }^{22}$ Three are exogenous to the pension scheme, the demographic risk, the macroeconomic risk and financial market risk. Two are endogenous, moral hazard and the political risk. How the pension scheme is designed matters for whether these risks are dealt with more or less efficiently.

The demographic risk, in addition to that inherent in the development of life expectancy at and after retirement, is that involved in the development of the labour force. The economic risk is broader, in that it encompasses $g+\lambda$. A basis for examining the economic and demographic factors is provided by the following macro and micro identities (see Palmer 1999):

\footnotetext{
${ }^{21}$ Holzmann (1997) concludes this was the most important externality accompanying the introduction of mandatory FDC in Chile.

${ }^{22}$ See Fox and Palmer (2001a).
} 
Contribution rate $=\frac{\bar{p}}{\bar{w}} * \frac{\text { pensioners }}{\text { contributors }}$

or for the average participant in the scheme

Contribution rate $=\frac{\bar{p}}{w} * \frac{\text { years in retirement }}{\text { years of work }}$.

where $\mathrm{p}$ and $\mathrm{w}$ with bars are the average pension and average wage in the economy. Financial balance in the sense of an unchanged contribution rate requires that benefits increase at the same rate as or slower than the contribution base. Abstracting from the problems discussed above that can give rise to imbalance that are captured by $\varphi_{t}$ in balancing NDC, and implicitly FDC, an unchanged contribution rate implies that years worked and in retirement adjust so as to maintain a constant dependency ratio, given adjustment of average benefits to life expectancy. This happens in the DC framework, but by definition not in the DB framework. In sum, NDC adjusts itself with changes in $g$ and $\lambda$, the latter either directly, or through balancing as in the Swedish model, but NDB does not. Hence, the demographic and economic risks are minimized in NDC, where NDB is highly exposed.

The financial market risk refers to the financial portfolio risk. The rate of return in the NDC scheme is by nature a diversification of the "portfolio" of all economic activity (including small enterprises), not just assets traded in the financial market. The price for this can be a rate of return below the financial market rate, and this creaming effect may be part of the explanation of why we observe higher rates of return in the formal financial markets during the twentieth century. The FDC financial market risk can be managed by portfolio diversification. Substantial financial market inflation and deflation constitute a risk for FDC and FDB schemes. A mix of NDC and FDC helps to alleviate the extreme risk of collapse, which can be very detrimental for the cohorts caught up in it, while it makes it possible to take advantage of the strong positive return that a financial portfolio can yield. Complete reliance on either would appear not to be optimal, although this is a separate topic in itself.

Fraud is a financial risk, in that it can occur with financial systems. It is probably more serious in countries with less developed legal institutions, legal cultures and the effective means to enforce the law. In order to cope with potential fraud, countries in Latin America and Eastern Europe that have introduced mandated financial schemes have also tended to 
introduce costly comprehensive supervisory procedures to detect fraud at an early stage. ${ }^{23}$ NDC is not exposed to fraud which - particularly in countries without a strong financial market culture - provides protection against fraud without costly protective measures.

Moral hazard occurs when people leave the workforce at a pre-determined age with a defined benefit. Exit reduces the size of the labour force, at the same time that pension commitments increase if the benefit itself is not based on life expectancy at retirement. Regardless of the pension system, the minimum age of retirement will determine when people begin to exit, and the benefit design what they can expect to receive. DC and DB differ in that DC bases the benefit explicitly on life expectancy, where as DB may or may not.

The recognition of claims is a political risk. Are the claims of participants better protected in private or publicly managed schemes? Changing DB rules changes the contract. DC schemes do not entail a specific benefit commitment, and by definition, the contract is possible to fulfil over generations. However, as we have discussed above, the government can partially nullify (tax) NDC as well as FDC account values. Seen in this light, perhaps the real difference between DB and DC is that the tax in the NDC and FDC context is explicit and its scale measurable, whereas in the DB context, it may not be explicit and the impact of the individual or cohort burden may be impossible to identify. DC provides more information for voters to react upon, which may provide a better shield against infringement (taxation) of accrued rights.

Furthermore, with defined benefit schemes, politicians can easily become the losers. Pensioners are interested in maintaining benefits, workers in keeping the costs down, and this pits the two segments of society against each other. ${ }^{24}$ From the point of view of voters, there will be default regardless of the decision.

In sum, the government can "default" in any formulation of a mandatory public scheme, in DB schemes by altering the conditions of the contract, but in both versions of DC schemes through taxation. The main difference is transparency, i.e. identification of who bears the burden.

There are other political risks. The necessity of of parametric change in DB schemes every once and awhile provides an opportunity for political bargaining on all terms of the

\footnotetext{
${ }^{23}$ In this context FDC can be considered superior to FDB because a straight-forward financial account system is more transparent.

${ }^{24}$ Usually the pensioners are a stronger lobby group than the workers, so promises accelerate public DB schemes. Workers may even tend to think that contributions come at the expense of profits, since the employer usually administrates the payments. A typical view among economists is that employers shift these costs to employees in the long run, through lower nominal wages or higher price increases, or both. This behaviour is also confirmed empirically (e.g. Palmer and Palme 1988).
} 
contract. In some political environments this also opens the door for special interest groups to demand that government grant them special privileges. In NDC and FDC the rules are set out clearly and there is no need for reopening the contract. ${ }^{25}$

\section{SOCIAL DISTRIBUTION}

The usual arguments for mandating some ground level of public pension coverage in old age the need to minimize free riding and individual myopic behaviour - are based on the idea that it is better to require people to pay something now, to avoid potential future taxes on future altruistic workers whose own preferences include helping the impoverished achieve a minimum consumption standard. Furthermore, to avoid additional taxes, due to free riding or myopic behaviour, life annuities are preferable to lump sum payments or phased withdrawals shorter than a life. In addition, with NDC individual account values must be converted into a life annuity. A lump sum, which some financial schemes allow, can give rise to poverty in very old age if recipients are not adequately frugal, and, thus, can give rise to a future tax, thereby creating additional free riding. In sum, the issue is to protect insiders against freeriding outsiders. ${ }^{26}$

The fact that a mandated (DC or DB) pension scheme may force people to save resources in present time that they would rather consume, as opposed to a voluntary scheme or no scheme at all and taking the risk as it comes - has an important ramification. The "taxed" worker - in terms of this violation of time preference - will have to work more or consume less when young. This may help explain why we observe such a large degree of informality in poorer countries with mandated schemes. ${ }^{27}$ It is often argued, however, that DC schemes minimize the propensity towards informality because of the feature that individual benefits are directly linked to the participant's own contributions (e.g. see Fox and Palmer $2001 \mathrm{a}$ and $2001 \mathrm{~b}$ for a discussion and other references).

In the NDC and FDC framework there is no redistributive ambition, other than redistribution over the individual's own lifecycle from working years to years of retirement. ${ }^{28}$

\footnotetext{
${ }^{25}$ A DB scheme cannot be run without exogenous interventions. Both NDC and FDC have built-in automatic stabilizers, so they can.

${ }^{26}$ In developing countries a mandate also establishes a formal framework into which the informal economy can enter with increasing economic development, although this is no guarantee that they will do so.

${ }^{27}$ For example, informality in Latin America, where many countries now have mandated financial account schemes, is on average around 30 per cent (Fox and Palmer 2001b), even in Chile.

${ }^{28}$ In mandated schemes unisex life expectancy is used to compute the annuity, which ceteris paribus, redistributes resources from men to women, as long as women live longer. More generally, groups that live longer are winners in all systems where an annuity or fixed benefit is paid out over the remaining lifetime from retirement. The same effect arises for persons who qualify for full benefits in a DB scheme.
} 
Instead, the government's redistributive policy is pursued through minimum income support or a guaranteed minimum pension. The latter can be formulated as a supplement to the DC benefit(s) up to the guaranteed amount. A guarantee is claimable first from a specific age and is financed through explicit taxes from general revenues. In principle, the minimum age at which a tax-financed guarantee can be claimed should be high.

In addition, social policy makers can transfer money from general tax revenues into the NDC or FDC schemes to finance "social" account values. It is necessary to transfer money into these DC systems, since every source of entitlement has to be accompanied by financing. Examples of situations that might be covered are time spent caring for younger children or sick relatives and military conscription, and time out of work for insured spells of sickness, unemployment and disability. In this way, insurance and its source of financing and social policy and its means of financing are kept separate, enhancing transparency.

As opposed to DC schemes, DB schemes contain built-in redistribution. Sometimes the redistributional mechanism is transparent and meets a specified political target, sometimes not. The simplest form of public defined benefit is a flat rate pension, which redistributes from persons with higher earnings to persons with lower earnings prior to retirement. A flat rate pension financed by a flat or progressive rate tax (or contribution rate) moves resources form the better to the poorer off by definition. However, many DB schemes do not have such clear redistributional profiles from the "rich" to the "poor," for example those based on final salary schemes, the best " $x$ " out of " $y$ " years, etc, which tend to benefit persons with higher earnings and shorter earnings careers. Because of this, it is difficult to understand claims that there is no real difference between NDC and NDB schemes (e.g. Cichon 1999 and Disney 2000).

There are political economy arguments too for financing transfers through the general budget of a nation, as is done in the FDC and NDC framework, with explicit separation of social insurance for old age from social policy goals. First, general revenues are collected out of a broader tax base than the payroll, and minimising payroll taxes minimises the wedge between labour costs and take-home pay. Second, the contribution rate for the pension insurance scheme is linear, while general taxes and other tax sources can be progressive, i.e. a relatively larger part of general revenues comes from the relatively better off, which is important for redistribution. ${ }^{29}$

\footnotetext{
${ }^{29}$ See also Góra (2001a).
} 
In sum, mandated DC schemes are simply life-cycle saving schemes for individuals, with no pretence to redistribute between individuals. They are mandated to help avoid the negative effects of free riding and myopic behaviour. However, distribution policy is moved over to the state budget, where decisions on benefits require a parallel decision on how they should be financed. DB schemes can include distributional mechanisms, but frequently with unintentional consequences.

\section{WHAT'S PRIVATE AND WHAT'S PUBLIC?}

In discussions of pension reform it is sometimes argued that what matters is to replace public with private schemes. "Privatize pensions" is frequently the panacea offered to solve the problems presently confronted by public systems. What is private and what is public, and what is the private attribute that is so desirable, if any? Several issues are identified and discussed here.

The first issue is private or and public management. The separate administrative functions $-e . g$. account keeping and provision of information, management of assets and the provision of insurance products - can be performed either by a public monopoly or private providers, regardless of the type of scheme. Private provision brings in contracts, a second issue, and implies that the claimant or government representative of the claimant is protected by civil contract law. The economic choice criterion is relative cost efficiency, but the popularity enjoyed by the private and public sectors, the degree of people's trust in these, and a country's tradition also matter.

The third issue has to do with claims or what we call the political risk already discussed under the topic of risks. The final issue has to do with assets in financial versus non-financial schemes, and has already been discussed. Financial schemes hold financial market assets, non-financial schemes do not.

Table. Private or public?

\begin{tabular}{lll}
\hline & NDC & FDC \\
Management & Public or private & Public or private \\
Contracts & Public or private & Public or private \\
Claims & Public or private & Public or private \\
Assets & Public & Public or private \\
\hline
\end{tabular}


To conclude what matters is not the difference between private and public.

Management, contracts and claims can be either public or private, and the asset underlying the scheme can be government bonds - marketed or unmarked, implicit Buchanan bonds - or non-governmental financial assets.

\section{CONCLUSIONS}

This paper has presented an economic framework for discussing the similarities and differences between pension schemes. The ideas are all to be found in the literature, but not consistently presented and discussed within an economic theoretic framework. This is what we have done here. In the 1990s, NDC emerged as a viable scheme, with a design that manages risks and eliminates the negative externalities associated with public NDB schemes in a manner similar to that of FDC schemes. However, FDC is potentially superior to NDC because it can create saving and promote financial market development, what we call positive externalities.

NDC can be viewed as being funded by a government bond earning a rate of return $\mathrm{g}+\lambda$. We argue that FDC schemes that hold government bonds entail a tax if the financial market bond rate is greater than $\mathrm{g}+\lambda$. NDC (and NDB) is robust to fraud and other ways of mismanaging financial accounts. In all other respects, NDC and FDC schemes are the same. Both NDC and FDC are financially stable, and because they are simply lifecycle saving schemes for individuals, they must be supplemented by social policy with distributional aims. However, the advantage of separating social insurance for old age from the social policy is that the latter can be discussed in a transparent environment, where each political decision carries a price tag.

Part of the logic of DC schemes (NDC and FDC) is the logic of separating the lifetime saving problem of individuals from the social political goals of redistributing income to the lifetime poor and financing other socially motivated transfers. This makes FDC and NDC systems transparent and economically efficiently, whereas DB schemes will have tax wedges, and may entail obscure and or unfair distribution rules resulting from the DB formulas.

The main conclusion of this paper is that NDC is a neutral in terms of externalities. NDC does not create the negative neutralities associated with DB schemes, nor does it give rise to the positive externalities associated with financial schemes.

Finally, because they follow the same economic logic, NDC and FDC fit well together and can provide a mix of the pension portfolio between a (unissued) Buchanan bond and equity financing. Combining them can be an efficient way to pool risks involved in each. 


\section{REFERENCES}

Buchanan, James M., 1968. "Social Insurance in a Growing Economy: A Proposal for Radical Reform", National Tax Journal, vol. 21, pp.386-95.

Chlon, Agnieszka, Marek Góra and Michal Rutkowski, 1999. "Shaping Pension Reform in Poland: Security through Diversity", World Bank Pension Reform Primer, Washington, D.C.

Cichon, Michael, 1999. "Old Wine in New Bottles?” International Social Security Review, vol. 52, no. 4 , pp. 87-105.

Disney, Richard, 2000. "Notional Accounts as a Pension Reform Strategy: An Evaluation." World Bank Pension Reform Primer, Washington, D.C.

Fox, Louise and Edward Palmer, 1999. "Latvian Pension Reform.” Social Protection Discussion Paper 9922. World Bank, Washington, D.C.

Fox, Louise and Edward Palmer, 2001a. "New Approaches to Multipillar Pension Systems:

What in the World is Going on?" in New Ideas about Old Age Security (Robert Holzmann and Joseph E. Stiglitz, eds.). The World Bank, Washington, D.C.

Fox, Louise and Edward Palmer, 2001b "Pension Reform in Europe in the 1990s and Lessons for Latin America" (with L. Fox). CEPAL - Serie Financianiento del desarrolo No. 113. Santiago:United Nations - ECLAC 2001.

Franco, Daniele, 2002, “Italy: A Never Ending Pension Reform” in Feldstein, M and H. Siebert (eds) Coping with the Pension Crisis: Where Does Europe Stand? University of Chicago Press, Chicago.

Góra, Marek and Michal Rutkowski, 1998. “The Quest for Pension Reform”, SP Discussion Paper No. 9815, World Bank Pension Reform Primer, Washington, D.C.

Góra, Marek, 2001a. "Polish Approach to Pension Reform", OECD Private Pension Systems, No.3, pp. 227-246, OECD, Paris.

Góra, Marek, 2001b. “Koszty, oszczędności oraz efekty zewnętrzne związane z wprowadzeniem nowego systemu emerytalnego", Zeszyty BRE Bank - CASE, No.57, pp.7-36.

Góra, Marek, 2002, Finansowanie przejścia od tradycyjnego do nowoczesnego systemu emerytalnego, Gospodarka Narodowa, nr 9, pp. 1-18.

Gruber Jonathon and David Wise, 1999, Social Security and retirement Around the World. National Bureau of Economic Research Conference Report. Chicago and London: University of Chicago Press. 
Hassler, John and Assar Lindbeck, 1997. "Optimal actuarial fairness in pension systems: A note," in Economic Letters, Vol. 55, pp. 251-255.

Holzmann, Robert, 1997. "Pension Reform, Financial Market Development and Economic Growth: Preliminary Evidence from Chile." IMF Staff Papers 44, No.2, pp.149-178.

Lindbeck, Assar and Mats Persson, 2002.’The Gains from Pension Reform.” Working Paper, Institute for International Economy, University of Stockholm.

Palmer, Edward and Mårten Palme, (1988). "A Macroeconomic Analysis of EmployerContribution Financed Social Security in Sweden" in A. Klevmarken and B. Gustafsson (eds.) The Political Economy of Social Security. Elsevier Science Publishers: Amsterdam.

Palmer, Edward, 1999. "Individual Decisions and Aggregate Stability in the NDC System." Processed at the World Bank.

Palmer, Edward, 2000. ”The Swedish Pension Reform - Framework and Issues.” World Bank Pension Primer, Washington, D.C.

Palmer, Edward, 2002. "Swedish Pension Reform - How Did It Evolve and What Does It Mean for the Future?" in Feldstein, M and H. Siebert (eds.) Coping with the Pension Crisis: Where Does Europe Stand? Chicago: University of Chicago Press.

Samuelson, Paul, 1958. “An Exact Consumption-Loan Model of Interest with or without the Social Contrivance of Money," Journal of Political Economy, pp. 219-34.

Settergren, Ole, 2001. "The Automatic Balansing Mechamism of the Swedish Pension System - a non-technical introduction," Wirtschaftspolitische Blätter 4/2001.

Valdes-Prieto, Salvador, 2000. "The Financial Stability of Notional Account Pensions", Scandinavian Journal of Economics, vol. 102, no. 3, pp. 395-417. 